\title{
Modern Ideas about Intellectual Disability in Medical Psychology in the Context of Non-Verbal Communication of Primary School Children
}

\author{
Oksana V. Zashchirinskaia*
}

\author{
Department of Pedagogics and Pedagogical Psychology, Saint Petersburg State University, Saint \\ Petersburg, Russian Federation
}

\begin{abstract}
Objective: The study of intellectual disabilities in children and their diagnosis has become more and more relevant in recent years. In the 21st century, in terms of diagnostics and the implementation of psychological influences, the problem of identifying the features of communication skills in children with intellectual disabilities becomes very significant and urgent.

Background: This study aims to review modern ideas about the role of intelligence in the development of communication. The methodological framework of this study was the combination of various theoretical methods of cognition. The author analysed the scientific literature of Russian and foreign researchers.

Method: The following methods of scientific cognition were used: data synthesis and analysis. In the process of writing this work on the modern ideas of scientists, according to the subject matter, the author studied the current level of research on this issue.

Results: The works of Russian and foreign scientists were considered, as well as conclusions, were drawn about the levels of study of the problem of intellectual disability in children.

Conclusion: The practical significance of this study lies in the identification of modern ideas about intellectual disabilities. The study and research of this subject will provide opportunities for the development of a programme of psychological influence on the optimisation of non-verbal communication of children with intellectual disabilities.
\end{abstract}

Keywords: Intelligence, intellectual disabilities, mental retardation, clinical psychology, mental development.

\section{INTRODUCTION}

Within the framework of this study, the investigation of the phenomenon of mental retardation is performed in the context of various scientific disciplines. In medicine, mental retardation is considered as a condition against the background of an organic disorder of the central nervous system, described by certain epidemiology, aetiology, pathogenesis, clinical picture, and comorbidity. Persistent and irreversible impairment of intelligence is regarded as a developmental pathology [1]. In clinical psychology, mental retardation is diagnosed from the standpoint of studying the dynamics of the course of cognitive, emotional, and behavioural processes in conditions of dysontogenesis. When describing this phenomenon, among other intellectual disorders, local pathological manifestations are indicated, as well as in the entire psyche as a whole.

In the context of studying the non-verbal communication of children of primary school age with intellectual disabilities, attention will be paid to mild mental retardation. And not only the features of

*Address correspondence to this author at the Saint Petersburg State University, Saint Petersburg, Russian Federation; Tel: +7812 36366 33; E-mail: zashchirinskaia5112@ubogazici.in communication against the background of mental underdevelopment will be considered. Also, the adaptive capabilities of children with the help of which it is possible to compensate for the limitations that arise in the presence of mental retardation are studied

From the standpoint of medical psychology, mental retardation is understood as a generalised pathology, which is expressed in intellectual underdevelopment and unformed adaptive abilities of a person [2, 3]. Within the framework of the International Classification of Diseases of the 10th revision adopted on the territory of the Russian Federation [1], it is customary to distinguish the following clinical forms of mental retardation (classifier code F70 - F79 according to ICD-10): mild mental retardation (F70), moderate mental retardation (F71), severe mental retardation (F72), as well as profound mental retardation (F73). Nowadays, this disease is extremely common worldwide and accounts for about $2-4.5 \%$ of the total population. The most common is a mild decline in intelligence $-75 \%$ to $90 \%$ of all cases of mental retardation, especially in countries with middle or lowincome populations [4].

The cause of general persistent mental underdevelopment can be congenital pathologies associated with mutations in the child's genome, 
causing either disturbance in the development of the central nervous system or leading to metabolic disturbances, and exogenous hazards that affected both the perinatal period, including various infectious diseases, exposure of the foetus to ionising radiation, birth trauma. In the early postnatal period, mental development is pathologically influenced by past infectious diseases, physical trauma, and other endogenous hazards, leading to persistent irreversible organic impairment of intelligence. External negative social factors that can cause mental retardation include long-term social deprivation, in which the adults pay practically no attention to the child since the early postnatal period, which is typical for dysfunctional families. Cases are also possible when endogenous and exogenous factors affect the development of mental retardation [2-5].

\section{METHODOLOGY}

The methodology of this paper is based on theoretical methods of scientific knowledge. In the context of this study, the following were used: theoretical analysis of the literature, synthesis, and analysis of data, system analysis of data. With the help of a theoretical analysis of scientific literature, the author studied the concepts and terms according to the subject matter. The study considers the concept of mental retardation, the process of intellectual disability, the specific features of communication of children against the background of mental underdevelopment, and adaptive capabilities for children with intellectual disabilities. The International Classification of Diseases of the 10th revision has been reviewed. The international classification of diseases distinguishes the following forms of mental retardation: mild mental retardation, moderate mental retardation, severe mental retardation, and profound mental retardation. Having studied this classification, it was concluded that currently, mild mental retardation is the most common form of mental retardation in children. The scientific articles of the researchers regarding the subject matter were considered within the framework of this study. The studies of foreign and Russian scientists are considered. Scientific publications, books, and practical manuals are reviewed. The information about children with mental retardation is analysed, theories, and proposals presented by the authors of the studies are considered.

This study used synthesis as a method of empirical research. It lies in the study of the phenomenon by combining its interconnected elements into a single whole. This method was used to study modern ideas about the problem of intellectual impairment in children of primary school age. The most pressing problems of children with intellectual disabilities were identified, and the possibilities for their solution were considered. The method of analysis is a method of scientific cognition, which is used to divide a phenomenon into its component parts. In the context of this study, data on non-verbal communication of children of primary school age with intellectual disabilities were analysed. The study considered individual components that directly affect the process of intellectual disability in children. Intellectual impairment has been viewed as a developmental pathology in a child. The search for possible solutions to problems for children with intellectual disabilities was carried out.

With the help of system analysis, the study investigated scientific publications of foreign scientists about mental retardation in children, its forms, and the possibilities of prevention. The study analysed the information on the mental characteristics of children who were clinically diagnosed with mental retardation. The analysis of scientific articles devoted to this problem allowed us to draw conclusions about the insufficient knowledge of this topic and the possible prospects for the modernization of clinical practice. Embregts considers the effectiveness of using a video feedback package and improving self-control in people with mild mental retardation. The results obtained by Embregts showed a statistically significant reduction in inappropriate behaviour during the procedure. The author noted that the total number of interactions was stable at different stages of the study. Maulik et al. conducted a meta-analysis and collated data from published literature on the subject matter and assessed the prevalence of mental retardation [4]. The authors noted that this meta-analysis is of particular relevance for public health and future research. The study analysed the works of Hronis, Roberts, and Kneebone, in which the authors investigate the neuropsychological profile of children and adolescents with mild to moderate intellectual disability. The research findings may provide a basis for the possible adaptation of cognitive-behavioural therapy in clinical practice. Kok and other researchers also studied the issue of mental retardation in children. Their work examines the problems of adaptation of children with mental retardation to the environment, as well as the fact that children with intellectual disabilities are at increased risk of developing mental disorders. 


\section{RESULTS}

\section{Mental Characteristics of Children Diagnosed with Mild Mental Retardation}

Due to its aetiology, mental retardation can occur in combination with other concomitant features of the psyche - speech disorders, the work of analysers (partial loss of vision, hearing, etc.), behaviours described within the framework of the concept of mental disorders [2, 3, 6]. The clinical picture of mental retardation is described by a slow, insufficiently differentiated reaction of children with mental retardation to stimuli [7]. The underdevelopment of mental activity comes to the fore, which is described by a generalisation and clearly manifests itself in the hierarchy of mental processes. The revealed violations, in combination with the specific features of the course of cognitive processes, lead to difficulties in the development of knowledge, skills, and abilities, as well as in the further adaptation of such children [8]. It is quite difficult for such children to single out the most important features of objects in the context of the problem being solved, to find commonalities among various objects, to generalise and, as a consequence, to apply mental operations, in particular the ability to carry out classification and abstraction [9]. Based on these disorders, in turn, an entire complex of disorders of a different type is developed, which are more expedient to consider with the help of clinical and psychological knowledge in order to assess the impact of these disorders on specific areas of the psyche [4].

The mental characteristics of children in the presence of a clinical diagnosis of "mental retardation" within the framework of medical psychology are considered in the context of a biopsychosocial approach. It offers a complex multi-level consideration of the interrelationships of the psychological, biological, and social levels of an individual's functioning with the use of structural-dynamic approach developed by O.V. Zashchirinskaia [10]. This approach includes the possibility of considering three components of the manifestation of mental development - cognitive, emotional-personal, and behavioural. The cognitive sphere of children with mental retardation is described, depending on the clinical form, by the consequences of the underdevelopment of abstract thinking: in such children, against the background of a decrease in the ability to generalise and abstraction, visual-effective, and partially visual-figurative thinking prevails, which imposes significant restrictions on the implementation of cognitive abilities [2-4, 6, 11-14]. Such children experience significant difficulties in their attempts to single out the most relevant characteristics of objects and situations among the set of characteristics to determine the general, most essential characteristics of the objects being cognised. Similar features are observed in children with mental retardation also in the process of perception, which is described by low differentiation and a reduced rate of the course of perceptual processes. In general, impaired cognitive processes are associated with a lack of randomness in their course [15].

Apart from impairments in the cognitive sphere, according to many authors $[2-4,6,8,11,14]$, children with mental retardation have underdeveloped and insufficient differentiation of social emotions. Behaviour with this decrease in intelligence differs from normative development by the presence of deviations in social manifestation due to pathological features of their mental organisation: disorders of the psychomotor sphere, coordination, speech, problems with voluntary memorisation, and attention against the background of a general decrease in self-regulation. It is important to note that specialists have noted combined motor skills and speech disorders in children with mental retardation. At the heart of these features is the undifferentiated response, in which the meanings of words differ in concreteness and affective experiences, life experience, and can arise in the speech repertoire upon the use of similar concepts. A child with mental retardation establishes simple and specific connections between the words studied and objects of the surrounding reality. Subsequently, in the cognitive sphere, the inability to abstract from particular meanings and operate with the polysemy of words and their figurative meaning becomes fixed [14]

Underdevelopment of the cognitive, emotionalpersonal, and behavioural spheres of the psyche is reflected in the interaction of children with mental retardation with peers and adults [15]. On the one hand, depending on the clinical form of mental underdevelopment, they turn out to be limited in mastering the skills of self-service and communication with people, which is especially noticeable in relation to the difficulties that arise in communication. On the other hand, when communicating with such children, many adults are guided by various prejudices and stereotypes and often ignore their special needs, creating conditions for the emergence of manifestations of social deprivation, which, in turn, slows down and complicates the socialisation of such children [2]. 
The analysis of the features of mental development of children with mild mental retardation indicates a decrease in the degree of impairment of the cognitive, emotional-personal, and behavioural spheres in such children compared to peers with moderate, severe, or profound mental retardation [16].

To a lesser extent, children with mild mental retardation have expressed disturbances in the emotional and motivational-volitional sphere, namely: reduced cognitive activity, cognitive underdevelopment is noted. Nondifferentiation of emotional manifestations in communication is observed to a lesser extent. However, a general decrease in intelligence (the IQ coefficient in such children is diagnosed in the range of 50-69 points), among other things, is expressed in a markedly reduced ability to abstract. This feature is key in the picture of mental retardation, and, as mentioned above, it causes all other disorders affecting the cognitive, emotional, and behavioural spheres of the psyche, as well as the functioning of the psyche as a whole. Therewith, mild mental retardation is described by a lesser degree of intellectual impairment, which in turn has a less pronounced effect on the indicated mental spheres, which, however, remain sturdily impaired [13].

\section{Teaching Children with Mild Mental Retardation and Their Adaptation in Society}

In accordance with the degree of intellectual decline, children with mild mental retardation are considered to be significantly more adapted and, when trained in special education, are subsequently able to acquire a profession and lead an independent life. They have a sufficient level of self-service skills. In general, the learning ability in school and the social adaptation of such children turn out to be limited, which is reflected in the difficulties of communication, lack of inclusion in the process of school education, lack of understanding of general cultural traditions and norms. Children with mild mental retardation, having reduced learning ability, experience significant difficulties in mastering a special educational programme and adapting to the conditions of school education in general [3, 17-19].

The diagnosis "mild mental retardation" is often compared with the diagnosis of "mixed specific disorders of psychological development" (F83, according to [1]), which is used in Russian medical psychology instead of the previously generally accepted term "mental retardation". According to ICD-
10 , this diagnosis combines heterogeneous disorders from F80 to F82 that occur together, affecting the cognitive, emotional, and behavioural spheres, in particular, speech and communication. With mixed specific psychological development disorders, intellectual disability is noted, which reduces the child's ability to learn. It may not have a generalised nature and is levelled by reaching puberty, in contrast to intellectual disabilities in the clinical diagnosis of F70 mild mental retardation [20]. Thus, specific mixed disorders of psychological development can be considered as an intermediate mental state between conditionally normative development and persistent irreversible impairment of the cognitive sphere.

When teaching children with mild mental retardation, it is important to pay attention not only to the primary impairment of intelligence but also to the mastery of work skills, self-service skills, as well as the potential for compensation for their intellectual underdevelopment. In these children, indicators of the behavioural, emotional, cognitive spheres, as well as motor disorders, directly cause socialisation problems [21]. Therewith, one of the difficulties for organising the education of children with mild mental retardation is that, with various aetiologies, there are pronounced manifestations of violations of cognitive functions and speech, as well as difficulties in communication and disorders of the emotional-volitional sphere.

The process of adaptation of children with mild mental retardation, particularly social behaviour in favourable conditions of development, can proceed quite well, which is fundamental in socialisation. Conversational skills, as well as the skills of elementary communication with targeted psychological influence, can be sufficiently developed, but the dynamics of their improvement is ambiguous, accompanied by regression in the absence of constant reinforcement of the results achieved $[13,14,19,22]$.

Taking into account the considered psychological characteristics of the development and education of children with mild mental retardation, methods of intervention are being developed that affect work with children and include, among other things, game techniques for mastering new information. These methods can both be applied individually and be aimed at correcting disorders of coping with specific difficulties, as well as group forms of psychological influence, comprehensively affecting all problem areas of mental development of these children [10, 23-25]. With mental retardation, depending on the degree of 
intellectual underdevelopment, the possibilities of further social adaptation remain. The criterion for assessing its success is psychosocial development based on interaction with others, and this, in turn, depends on the development of verbal and non-verbal communication skills [10, 24, 26-28]. Social adaptation is defined as the process of an individual's adaptation to changing environmental conditions [17, 18, 29, 30]. For children with mild mental retardation, an important aspect of the adaptation process is the mastery of independent communication, focused on certain conventional norms that regulate their behaviour and the development of motivational-volitional processes.

Thus, mild mental retardation is a mental state that is primarily reflected in the intellectual abilities of children and leads to the development of cognitive, behavioural, and emotional spheres according to the dysontogenic type. Persistent intellectual underdevelopment significantly limits the possibilities of integrating such children into the social environment [31].

Within the framework of clinical psychology, specialists carry out work not only considering the disturbing aspects of the psyche but primarily with reliance on safe processes in order to find and implement compensatory mechanisms that contribute to increasing the adaptive abilities of such children [32]. The psychological impact aimed at the development of these abilities implies active interaction with the child, which leads to its purposeful inclusion in the process of social communication. To increase communication effectiveness as a compensatory derivative of socialisation, it is important to study its features in children with mild mental retardation [33].

\section{DISCUSSION}

Many foreign and Russian researchers have considered modern ideas about intellectual disabilities in children. Below is the review of some of their studies. In the study Prevalence of intellectual disability: a meta-analysis of population-based studies, the authors conducted a meta-analysis and comparison of data from previously published literature on intellectual disabilities and assessed the prevalence of mental retardation the studies presented [4]. The authors' sample provides an overview of studies published between 1980 and 2009, as well as data on population groups that represent an understanding of the overall estimate of the prevalence of mental retardation in the population. Consequently, from the information presented in this study, the descriptions of the problem of intellectual disability varied depending on the material support of the country, the territorial location, and the age group of the studied population. The highest rates were observed in low- and middle-income countries. Studies that were based on case-finding using psychological scores or scales indicated a higher prevalence compared to studies with the use of standard diagnostic systems and tools for identifying mental retardation. The meta-analysis presented in this study is of particular relevance to the international health care system and future research.

In the study by Embregts, Effectiveness of video feedback and self-management on the inappropriate social behaviour of youth with mild mental retardation, the effectiveness of a package of video materials for feedback and self-control is considered on the example of various types of behaviour of six young people with mild mental retardation [25]. The experiment procedure included video filming the participants' inappropriate behaviour, the next step for the researchers was to talk with the participants in order to convince them to control themselves and record their behaviour on a video camera, and then the participants were given the opportunity to evaluate their behaviour according to certain criteria and redirect themselves towards the appropriate behaviour. The researcher's results indicated a statistically significant reduction in inappropriate behaviour during the procedure.

The authors of the article "A review of cognitive impairments in children with intellectual disabilities: Implications for cognitive behaviour therapy" examine the neuropsychological profile of children and adolescents with mild to moderate intellectual disabilities to find out the best ways to adapt cognitive behavioural therapy for children and adolescents with these problems [34]. The authors note that children with mental retardation have significant attention deficit, learning difficulties, impaired memory, executive functions, and speech. These impairments can negatively affect outcomes during cognitive behavioural therapy. Researchers are making proposals for adapting therapy to address this wide range of disorders. The authors note that many cognitive factors need to be considered when modifying cognitivebehavioural therapy for children with intellectual disabilities. Moreover, they point out that further research is needed to test the effectiveness of modified cognitive behavioural therapy in practice. This study provides a framework for the possible adaptation of cognitive-behavioural therapy in clinical practice. 
The authors of the study The effectiveness of psychosocial interventions for children with a psychiatric disorder and mild intellectual disability to borderline intellectual functioning: $A$ systematic literature review and meta-analysis, studied and conducted a meta-analysis of more than a thousand scientific articles and publications on the problems of children with mental retardation [35]. The results of this study suggest that children with mental retardation often experience difficulties in adaptation in society. Several studies that were analysed by the authors indicate that children with intellectual disabilities are at increased risk of developing mental disorders. The study was aimed at the systematic assessment of qualitatively based research on the effectiveness of psychosocial interventions specifically aimed at mental disorders in children with intellectual disabilities. The study results showed that most of the published empirical material has many limitations and that the methodological differences between studies are significant.

In the article Caring for children with an intellectual disability: An exploratory qualitative study, the authors focus on the upbringing of children with mental retardation. They note the difficulties faced by the parents of such children, and especially the mothers of children with mental retardation [36]. The study emphasises that people who do not have children with intellectual problems, as well as people who have not experienced such violations, do not understand what the parents of such children go through. In this case, it is considered necessary to constantly cooperate between government departments, such as the ministries of health and social development, to work with the relevant non-governmental organisations. It is important to raise awareness about mental retardation among people. The authors suggest that informing society about the causes and consequences of stigmatisation and isolation of persons with mental retardation will have a beneficial effect on the position of children and their parents in society.

\section{CONCLUSIONS}

This study theoretically examines the issue of the features of non-verbal communication of primary school children with intellectual disabilities. A variety of theoretical approaches to the study of mild mental retardation was investigated. A review of literary sources indicated relatively sufficient research into the issue of communication of children with mental retardation with adults and peers. However, the specificity of their non-verbal communication remains understudied. Children diagnosed with mild mental retardation display impairments in the cognitive sphere, underdevelopment, and insufficient differentiation of social emotions. The behaviour in the presence of such a diagnosis may differ from conventionally normative manifestations. There is a reduced speed of response and unstable activity against the background of their mental organisation's pathological features. Disorders of the psychomotor sphere, coordination, and speech are observed. In such children, they are often combined with problems of voluntary memorisation and attention in the presence of a general decrease in selfregulation. Children diagnosed with mild mental retardation establish simple and concrete connections between words and objects of the surrounding reality. Underdevelopment of the cognitive, emotionalpersonal, and behavioural spheres in children with this diagnosis often affects their communication with peers and adults.

In the context of this study, the features of teaching children with mental retardation are analysed. The problems of adaptation of such children in society are presented. In the case of organic impairment of intelligence, it is important to address not only the persistent cognitive limitations but also the assimilation of work skills, self-service skills, and the potential for compensation for their intellectual underdevelopment. In children with mild mental retardation, the process of adaptation and social behaviour in favourable conditions of development can be carried out quite well, which is the basis for socialisation in society. An important aspect of adaptation for children with this diagnosis is mastering the skills of independent communication. Psychological impact involves active interaction with the child. In the future, this will ensure the inclusion of the child in the processes of social communication.

This study discusses the work of researchers on similar subjects. After analysing the publications of foreign and Russian researchers, conclusions were made about the modern concept of intellectual impairment in children of primary school age in medical psychology. At this stage, the problem of intellectual disability in children is understudied. Most psychologists are inclined to believe that this issue is a priority in international health care and the development of the social environment for persons with intellectual disabilities. 


\section{ACKNOWLEDGEMENTS}

None.

\section{REFERENCES}

[1] International statistical classification of diseases and related health problems 10 th revision. Volume 1 Tabular list Fifth edition 2016. About ICD10data.com. Available from: http://www.icd10data.com/About.

[2] Lebedinskaya KS, Lebedinsky VV. Mental developmental disorders in childhood and adolescence. Moscow: Akademicheskiy proekt 2011

[3] Mamaichuk II. Psychological assistance to children with developmental problems. Saint Petersburg: Rech 2001.

[4] Maulik PK, Mascarenhas MN, Mathers CD, Dua T. Prevalence of intellectual disability: a meta-analysis of population-based studies. Research in developmental disabilities 2011; 32 (2): 419-436. https://doi.org/10.1016/j.ridd.2010.12.018

[5] Ivanov ES, Isaev DN. Mental retardation: content, definition and modern theories of mental retardation. Homeschooling and Rehabilitation for Mentally Retarded Young People: A Guide for Parents. St. Petersburg: Publishing house of the St. Petersburg Association of Public Associations of Parents of Disabled Children "GAOORDI" 2000.

[6] Zmanovskaya EV. Deviantology. Moscow: Publishing Center "Akademiya" 2004.

[7] Upreti R, Singh R. Impact of Social Class on the Behavioural Skills of Mentally Challenged Children. Journal of Human Ecology 2016; 53(1): 65-73. https://doi.org/10.1080/09709274.2016.11906957

[8] Skorobogatova NV, Likhacheva NL. Theoretical and methodological approaches to the study of the psyche of children with intellectual disabilities. Shadrinsk: Shadrinsk State Pedagogical University 2015.

[9] Bhaumik S, Kiani R, Michael DM, Gangavati S, Khan S, Torales J, Ventriglio A, Javate KR. Intellectual disability and mental health: an overview. International Journal of Culture and Mental Health 2016; 9(4): 417-429.

https://doi.org/10.1080/17542863.2016.1228687

[10] Zashchirinskaia OV. Clinical and psychological aspect of communicative and personal development of children with mental retardation. Petersburg psychological journal 2013; 2: $1-14$.

[11] Zabramnaya SD, Isaeva TN. Issues of studying children with moderate and severe mental retardation. Special children in society: a collection of scientific reports and abstracts of speeches by the participants of the I All-Russian Congress of Defectologists (Moscow, October 26-28, 2015). Moscow: ANO "NMC "SUVAG", 2015, pp. 85-88.

[12] Zakrepina AV. Pedagogical assistance to the family in the upbringing of a preschool child with moderate mental retardation. Defectology 2004; 2 : 33-39.

[13] Broman SH. Retardation in young children: a developmental study of cognitive deficit. London: Routledge 2013. https://doi.org/10.4324/9780203056868

[14] Rosenberg S, Abbeduto L. Language and communication in mental retardation: Development, processes, and intervention. New Jersey: Psychology Press 2013. https://doi.org/10.4324/9780203771624

[15] Alnahdi $\mathrm{GH}$. The interaction between knowledge and quality of contact to predict Saudi university students' attitudes toward people with intellectual disabilities. International Journal of Developmental Disabilities 2019. https://doi.org/10.1080/20473869.2019.1638582
[16] Puzanov BP. Teaching children with intellectual disabilities (oligophrenopedagogy). Moscow: Akademiya 2001.

[17] Maller AR. Social education and training of children with developmental disabilities. Moscow: ARKTI 2000.

[18] Maller AR. The problem of integration of children with severe developmental disorders. Special education 2015; 1(11): 190-193.

[19] Rogozhina EA, Ivanova VA. Methods for the development and correction of social and everyday skills of mentally retarded children. International Journal of Experimental Education 2016; 12-2: 183-185.

[20] Salvador-Carulla L, Martínez-Leal R, Heyler C, AlvarezGalvez J, Veenstra MY, García-Ibáñez J, Van Schrojenstein Lantman-de Valk HMJ, Torr J, Munir K, Bertelli M, Carpenter $\mathrm{S}$. Training on intellectual disability in health sciences: The European perspective. International Journal of Developmental Disabilities 2013; 61(1): 20-31. https://doi.org/10.1179/2047387713Y.0000000027

[21] Jackson R. Politics and intellectual disability in England: a historical perspective. International Journal of Developmental Disabilities 2016; 63(1): 52-58. https://doi.org/10.1080/20473869.2015.1107364

[22] Savateeva AL, Tikhomirova LF, Tishinova EA. Establishment of a socialising correctional and developmental environment for children with moderate and severe mental retardation in an educational institution. Yaroslavl Pedagogical Bulletin 2015; 4: 143-151.

[23] Baryaeva LB, Zarin AP. Teaching role-playing games for children with intellectual development problems. St. Petersburg: A. I. Herzen Publishing House of the RGPU "SOYUZ" 2001.

[24] Lamminpia AM, Zashchirinskaia OV, Shelepin YuE. Psychophysiological analysis of the processes of reading and understanding texts. Human physiology 2015; 41(2): 23. https://doi.org/10.1134/S0362119715020097

[25] Embregts PJ. Effectiveness of video feedback and selfmanagement on inappropriate social behavior of youth with mild mental retardation. Research in Developmental Disabilities 2000; 21 (5): 409-423. https://doi.org/10.1016/S0891-4222(00)00052-4

[26] Ivanova SS. Specificity of communication of adolescents with mental retardation. The current state of psychology and pedagogy. Ufa: Aeterna 2015.

[27] Pronyaeva SV. Development of communication skills in preschool children. Ekaterinburg: Shadrinsk State Pedagogical University 1999.

[28] Shpek O. People with mental retardation: training and education. Moscow: Academy 2003.

[29] Isaev DN. Psychosomatic approach and model of psychosomatic disorders in children and adolescents. Clinical psychology 2003; 2: 148-152.

[30] Shipitsyna LM. An uneducated child in the family and society. Socialisation of children with intellectual disabilities. Saint Petersburg: Rech 2005.

[31] John A, Montgomery D. Parental Explanatory Models of Child's Intellectual Disability: A Q Methodology Study. International Journal of Disability, Development and Education 2015; 63(3): 293-308. https://doi.org/10.1080/1034912X.2015.1085001

[32] Bhaumik S, Tromans S, Gangadharan SK, Kapugama C Michael DM, Wani A, Michael G, Kiani R, Ventriglio A. Intellectual disability psychiatry: a competency-based framework for psychiatrists. International Journal of Culture and Mental Health 2017; 10(4): 468-476. https://doi.org/10.1080/17542863.2017.1322624

[33] Wark S. Does intellectual disability research consider the potential impact of geographic location? Journal of Intellectual \& Developmental Disability 2017; 43(3): 362-369. https://doi.org/10.3109/13668250.2017.1310826 
[34] Hronis A, Roberts L, Kneebone II. A review of cognitive impairments in children with intellectual disabilities: Implications for cognitive behaviour therapy. British Journal of Clinical Psychology 2017; 56(2): 189-207. https://doi.org/10.1111/bjc.12133

[35] Kok L, van der Waa A, Klip H, Staal W. The effectiveness of psychosocial interventions for children with a psychiatric disorder and mild intellectual disability to borderline intellectual functioning: A systematic literature review and meta-analysis. Clinical Child Psychology and Psychiatry 2015; 21(1): 156-171.

https://doi.org/10.1177/1359104514567579

[36] Sadiki TG, Mashegoane S. Caring for children with an intellectual disability: An exploratory qualitative study. Journal of Psychology in Africa 2019; 29(2): 191-194. https://doi.org/10.1080/14330237.2019.1603020

Received on 30-10-2020

DOI: https://doi.org/10.6000/2292-2598.2020.08.04.1

(C) 2020 Oksana V. Zashchirinskaia; Licensee Lifescience Global.

This is an open access article licensed under the terms of the Creative Commons Attribution Non-Commercial License (http://creativecommons.org/licenses/by-nc/3.0/) which permits unrestricted, non-commercial use, distribution and reproduction in any medium, provided the work is properly cited. 